\title{
Educational and Ethical Considerations for Genetic Test Implementation Within Health Care Systems
}

Emma Kurnat-Thoma ${ }^{1,2, *}$

\begin{abstract}
Introduction: The precision medicine (PM) era presents unprecedented proliferation of genetic/genomic initiatives, information, and bioinformatic tools to enhance targeted molecular diagnosis and therapeutic treatments. As of February 29, 2020, the National Institutes of Health (NIH) National Center for Biotechnology Information (NCBI) Genetic Testing Registry contained 64,860 genetic tests for 12,268 conditions and 18,686 genes from 560 laboratories, and the Food and Drug Administration had 404 entries for pharmacogeneomic biomarkers used in drug labeling. Population-based research initiatives including NIH's All of Us and Veterans Affairs' Million Veteran Program, and the UK Biobank, combine use of genomic biorepositories with electronic medical records (i.e., National Human Genome Research Institute's [NHGRI's] electronic Medical Records and Genomics [eMERGE] Network). Learning health care systems are implementing clinical genomics screening programs and precision oncology programs. However, there are insufficient medical geneticists, nurse geneticists, and genetics counselors to implement expanding number of clinical genetic tests that are required for PM implementation.

Methods: A scoping review of current (2014-2019) trends in U.S. genomic medicine translation, PM health care provider workforce education and training resources, and genomic clinical decision support (CDS) implementation tools was conducted.

Results: Health care delivery institutions and systems are beginning to implement genetic tests that are driving PM, particularly in the areas of oncology, pharmacogenetics, obstetrics, and prenatal diagnostics. To ensure safe adoption and clinical translation of PM, health care systems have an ethical responsibility to ensure their providers and front-line staff are adequately prepared to order, use, and interpret genetic test information.

Conclusion: There are a number of high-quality evidenced-based educational resources and CDS tools available. Strong partnerships between health care system leaders, front-line providers and staff coupled with reasonable goal setting can help drive PM translation interests.
\end{abstract}

Keywords: ethical legal social implications; genetic tests; health care provider training and education; health care system implementation

\section{Introduction}

Precision medicine (PM) is an approach to treatment and prevention of disease that takes into account a patient's genes, lifestyle, and environmental characteristics. ${ }^{1}$ The PM era presents unprecedented proliferation of genetic/genomic information and bioinformatic tools to enhance molecular diagnosis and therapeutic treat- ments. There has been rapid growth in both number of genetic tests and Food and Drug Administration (FDA) approvals for drugs with pharmacogenetic labeling information. As of February 29, 2020, the National Institutes of Health (NIH) National Center for Biotechnology Information (NCBI) Genetic Testing Registry contained 64,860 genetic tests for 12,268 conditions

\footnotetext{
'Department of Intramural Research, DHHS/NIH/NINR, Bethesda, Maryland, USA.

${ }^{2}$ School of Nursing and Health Studies, Georgetown University, Washington, District of Columbia, USA

*Address correspondence to: Emma Kurnat-Thoma, PhD, MS, RN, Department of Intramural Research, DHHS/NIH/NINR, Building 10, Clinical Center, Room 2N116, Bethesda, MD 20892, USA, E-mail: emma.kurnat-thoma@nih.gov; elk65@georgetown.edu
}

(C) Emma Kurnat-Thoma 2020; Published by Mary Ann Liebert, Inc. This Open Access article is distributed under the terms of the Creative Commons License (http://creativecommons.org/licenses/by/4.0), which permits unrestricted use, distribution, and reproduction in any medium, provided the original work is properly cited. 
and 18,686 genes from 560 laboratories, and the FDA had 404 entries for pharmacogenomic biomarkers used in drug labeling., ${ }^{2,3}$

Population-based biobank research initiatives including NIH's All of Us, Veterans Affairs' Million Veteran Program, and the UK Biobank combine use of genomic biorepositories with electronic medical records (i.e., National Human Genome Research Institute's [NHGRI] electronic Medical Records and Genomics [eMERGE] Network) to gain novel insights into candidate genes targets and complex gene-lifestyle interactions fueling development of chronic multifactorial diseases. ${ }^{4-6}$ Learning health systems are beginning to implement clinical genomics screening programs to identify and reduce patient risk for development of adverse outcomes and diseases such as familial hypercholesterolemia and hereditary cancer syndromes, and PM-based treatments for oncology community health care settings. ${ }^{7,8}$

Although these large-scale research initiatives began the PM movement, the field is rapidly evolving and broadening beyond genetics/genomics to include information generated from wearable sensors and digital health devices, network biology and systems medicine, polygenic risk score prediction algorithms, bioinformatics data science and machine learning methodologies, and multiomics profiling for a variety of health and disease states (Table 1). ${ }^{9-15}$

Artificial intelligence-the use of computing frameworks, algorithms, and theories to facilitate tasks that normally require human reasoning and decision making, understanding, or perception to include techniques such as machine learning and natural language processing-is emerging as a key analytic tool to manipulate and derive meaningful and actionable insights within the vast amounts of big data from whole genome sequence, multiomics data, electronic health records (EHRs), and others. ${ }^{23}$

Novel genetic/genomic/-omics insights gleaned from technological, engineering, and computer science approaches to identify disease biology mechanisms, predict onset, and implement targeted treatments are envisioned to shift health care from a reactive practice model to a proactive model. ${ }^{9,10}$ All health care paradigms utilizing genomic and molecular -omic data listed in Table 1 require the use of genetic tests, which are defined as "analysis of human DNA, RNA, chromosomes, proteins, and certain metabolites in order to detect heritable disease-related genotypes, mutations, phenotypes, or karyotypes for clinical purposes." 24
Table 1. Current and Emerging Terminology, Paradigms in Genomic Health Care

\begin{tabular}{|c|c|}
\hline Term & Definition \\
\hline $\begin{array}{l}\text { Genomic } \\
\text { medicine }\end{array}$ & $\begin{array}{l}\text { "Emerging medical discipline that involves using } \\
\text { genomic information about an individual as part of } \\
\text { their clinical care (e.g., for diagnostic or therapeutic } \\
\text { decision-making) and the health outcomes and policy } \\
\text { implications of that clinical use."16 }\end{array}$ \\
\hline $\begin{array}{l}\text { Network } \\
\text { medicine }\end{array}$ & $\begin{array}{l}\text { "Emerging field that combines systems biology and } \\
\text { network science. It runs counter to the prevailing } \\
\text { scientific reductionist trend that dominates current } \\
\text { medical research on disease etiology and treatment. } \\
\text { Reductionism relies on single molecules or single } \\
\text { genes to provide comprehensive and robust insights } \\
\text { into the pathophysiology of complex diseases. } \\
\text { Similarly, current drug development methodologies } \\
\text { target single molecules that very frequently fail } \\
\text { because of the unforeseen and unintended effects } \\
\text { that result from the application of this piecemeal } \\
\text { approach to pharmacology. Emphasizes a more } \\
\text { holistic approach through the identification and } \\
\text { investigation of networks of interacting molecular and } \\
\text { cellular components. When network medicine is } \\
\text { integrated into biomedical research, it has the } \\
\text { potential to transform investigations of disease } \\
\text { etiology, diagnosis, and treatment." }{ }^{11,17}\end{array}$ \\
\hline $\begin{array}{l}\text { Personalized } \\
\text { medicine }\end{array}$ & $\begin{array}{l}\text { "Emerging practice of medicine that uses an } \\
\text { individual's genetic profile to guide decisions made } \\
\text { in regard to the prevention, diagnosis, and treatment } \\
\text { of disease. Knowledge of a patient's genetic profile } \\
\text { can help doctors select the proper medication or } \\
\text { therapy and administer it using the proper dose or } \\
\text { regimen."18 }\end{array}$ \\
\hline $\begin{array}{l}\text { Precision } \\
\text { medicine }\end{array}$ & $\begin{array}{l}\text { "An emerging approach for disease treatment and } \\
\text { prevention that takes into account individual } \\
\text { variability in genes, environment, and lifestyle for each } \\
\text { person."1 In cancer, precision medicine "uses specific } \\
\text { information about a person's tumor to help diagnose, } \\
\text { plan treatment, find out how well treatment is working, } \\
\text { or make a prognosis."19 }\end{array}$ \\
\hline $\begin{array}{l}\text { Systems } \\
\text { medicine }\end{array}$ & $\begin{array}{l}\text { "New and emerging field that leverages complex } \\
\text { computational tools to develop personalized } \\
\text { assessments of disease risk and potential } \\
\text { management options. Systems medicine seeks to } \\
\text { enhance individualized diagnosis, prognosis, and } \\
\text { treatment options. The introduction of Big Data has } \\
\text { begun to require new types of physicians and } \\
\text { biomedical scientists, which exploit modern } \\
\text { computational sciences to process and analyze } \\
\text { enormous quantities of information." } 9,10,20\end{array}$ \\
\hline $\begin{array}{l}\text { Precision } \\
\text { health }\end{array}$ & $\begin{array}{l}\text { "Precision health is broader-it includes precision } \\
\text { medicine but also approaches that occur outside the } \\
\text { setting of a doctor's office or hospital, such as disease } \\
\text { prevention and health promotion activities." This } \\
\text { includes using targeted health information from } \\
\text { patients' wearable sensors, implantable monitoring } \\
\text { devices, and mobile devices for health prevention } \\
\text { interventions." }\end{array}$ \\
\hline $\begin{array}{c}\text { Precision } \\
\text { public } \\
\text { health }\end{array}$ & $\begin{array}{l}\text { "Improving the ability to prevent disease, promote } \\
\text { health, and reduce health disparities in populations by } \\
\text { applying emerging methods and technologies for } \\
\text { measuring disease, pathogens, exposures, behaviors, } \\
\text { and susceptibility in populations; and developing } \\
\text { policies and targeted implementation programs to } \\
\text { improve health." } 22\end{array}$ \\
\hline
\end{tabular}

Network medicine definition quote is verbatim from Harvard Catalyst, precluded by Chan and Loscalzo. ${ }^{11}$ Systems medicine definition quote is verbatim from 1st International Conference in Systems Network Medicine Conference, precluded by Auffray et al. ${ }^{9}$ and Auffray. ${ }^{10}$ 
It is broadly recognized that genetics/genomics health care professionals are most readily able to use and to guide implementation of genetic tests into health care workflows; however, their numbers and scope are limited. Thus ensuring adequate workforce capacity and clinician education/training in these areas (for both genetics and nongenetics providers) is an ethical imperative to ensure clinical translation of PM across populations and within communities.

When the U.S. Congress appropriated funding for the Human Genome Project in 1990, a portion of its funding was devoted to the ethical, legal, and social implications (ELSI) of genetics/genomics research. In the light of any rapidly evolving biomedical scientific field, but particularly PM, there is an ethical duty to consider the implementation impacts of those technologies upon patients, their families, and society as a whole. ${ }^{25}$ The NHGRI ELSI portfolio has expanded since its initial funding and now spans multiple domains, including the implementation of genetic/genomic tests into health care settings and health systems so as to ensure fair access, use, and reimbursement. ${ }^{26}$

In accordance with these stated priorities, a scoping review was conducted with the following research question: "what are the current trends in U.S. genetic test use, genetics/genomics healthcare workforce education and training, and available clinical translation tools for healthcare systems?" Highlights from this article were presented as part of the "Ethics and Educational Considerations in the Era of Precision Medicine" panel on September 12, 2019, at the 1st International Conference in Systems and Network Medicine, Applications of Systems Science and Thinking to Biomedicine. ${ }^{20}$

\section{Methods}

A scoping review was performed to examine current trends (2014-2019) in U.S. health system genetic test use, health care provider workforce education and training in genetics/genomics, and available clinical decision support (CDS) tools for PM implementation. Biomedical and nursing databases searched included PubMed, CINAHL, and Google Scholar for international English articles of quantitative (clinical trials, implementation pilots, meta-analyses, and reviews), qualitative, and mixedmethod research studies. MeSH search terminology criteria included Clinical Laboratory Improvement Amendments (CLIA)-certified laboratory genetic tests, health system implementation, genetic test implementation, ELSI, precision medicine/precision health genomic medicine implementation, workforce development, and CDS.
Specific health care disciplines reviewed included physicians, genetics counselors, and nurses, including gray literature on relevant credentialing and licensing statistics. Of the total 6242 records that were identified, 592 abstracts were reviewed, 186 full length reports and articles were read, and 51 full length articles were selected for the final scoping review. An additional 29 online resources for U.S. health system implementation of genetic tests were identified and practicable implementation frameworks with opensource tools highlighted.

\section{Results}

\section{Genetic test use trends in the U.S. health}

\section{care system}

Use of genetic tests can be broadly categorized into diagnostic, predictive, and reproductive applications; however, to meet standards of clinical safety and quality, a genetic test must show sufficient analytical validity, clinical validity, and clinical utility before clinical translation and implementation can occur within regulatory and payer coverage frameworks. ${ }^{24}$

Genetic tests that incorporate multiomic information and the CDSs required for their implementation will still be expected to meet these performance standards, while also demonstrating sufficient economic value relative to costs. ${ }^{27}$ The Centers for Disease Control and Prevention's (CDC) Public Health Genomics and Precision Health Knowledgebase curates various genetic test evaluation frameworks and evidentiary reports for genetic test performance outcomes for a wide range of health conditions, patient populations, and clinical settings. ${ }^{28,29}$

Although the number of genetic tests from CLIAcertified laboratories has increased in the NCBI Genetic Test Registry, these data do not provide an indication of current test utilization and spending within the U.S. health care landscape. An examination of the health care market diffusion patterns for various types of genetic tests and their associated clinical domain applications and challenges would help provide a roadmap for which to begin to prepare for the more technologically and computationally intensive multiomics translational tests.

A recent study of a U.S. commercial payer database spanning 28 health plans, all 50 states, and $\sim 40$ million covered lives reported a total of 75,000 genetic tests, with 14,000 new CLIA-certified laboratory genetic tests (single and multiple genes, exomes, whole genome, microarrays, sequencing, karyotype, and 
circulating cell-free DNA) coming onto market during 2014-2017, and $\sim 10$ new genetic tests coming onto the market daily. ${ }^{30}$ Claims were curated into clinical domains by current procedural terminology (CPT) code and laboratory identification number to analyze genetic test utilization and spending patterns by quarter for the 3-year study period. Prenatal tests (33-43\%), hereditary cancer tests $(\sim 30 \%)$, oncology diagnostics and treatment $(\sim 10 \%)$, and pharmacogenetic tests $(<5 \%)$ accounted for the highest percentage of U.S. genetic test spending.

When reimbursed, genetic tests for diagnostics have strong rates and new CPT codes incorporating nextgeneration sequencing are coming online annually and becoming integrated into electronic medical records and payment systems. In 2018, 30 new CPT codes specific to PM (primarily oncology) were added, with CPT code 8146 for exome sequencing analysis with a maximum allowable limit of U.S. $\$ 12,000{ }^{31}$ However, there are a wide range of incompatibilities between the evidence review process utilized within the insurance industry and the advanced technologies utilized in PM genetic tests. A review of three insurance coverage framework approaches with Medicare's national coverage determination process identified a number of possible evidence review pathways that could be revised to better allow for expanded access to nextgeneration tumor sequencing genetic tests. ${ }^{32}$ It should be noted that although genetic test use and reimbursement cost trends do not constitute PM directly on their own, they are an indication of the foundational health system tools and architectural components required for PM implementation.

\section{Workforce development}

Mechanisms for ensuring adequate health care provider training in genetics/genomics are widely recognized as including academic and residency programs subject to accreditation requirements, licensure and specialty certification examination proficiency, continuing education licensure requirements, and pointof-care education mechanisms embedded within health care system information technology infrastructure. Table 2 highlights salient health care provider education and training resources by professional domain. Genetics/genomics education competencies and frameworks are available for generalist and specialty medical practice areas, for nongenetic health professionals, and for providers who received education and training before the PM movement. ${ }^{33-35}$
An adequate supply of health care providers with sufficient education and training to use genetic/genomic information in an ethical and responsible way that respects the dignity, privacy/confidentiality, and welfare of patients and their families, particularly marginalized subpopulations, is an important priority in biomedical technology dissemination. However, the segment of the health care workforce classically trained in genetics/genomics is routinely identified as insufficient for wide scale PM implementation. ${ }^{36-38}$ To ensure adequate diffusion of this valuable specialty into underresourced areas as the PM movement expands, this could be an area that may benefit from a more focused and structured workforce development analysis initiative, such as the process used by the U.S. Health Resources and Services Administration's (HRSA) National Center for Health Workforce Analysis. ${ }^{39}$

Physicians. Despite its recognized importance, number of medical geneticists and medical trainees entering clinical genetics is low, and approximately two-thirds of medical geneticists are approaching retirement age. ${ }^{40-42}$ As of January 2018, the American Board of Medical Genetics and Genomics reported a total of $n=2937$ diplomates $(n=1583$ MD clinical genetics and genomics; $n=155 \mathrm{PhD}$ medical genetics; $n=323$ clinical biochemical genetics; $n=775$ clinical cytogenetics and genomics; $n=743$ clinical molecular genetics and genomics, and $n=49$ clinical biochemical $/$ molecular genetics; $n=63$ medical biochemical genetics; $n=9$ molecular genetic pathology). ${ }^{43}$ To increase physician trainees entering this specialty, a number of career development strategies and educational framework mechanisms are proposed, with a particular emphasis on development of premedical undergraduate genomics curriculums. ${ }^{37,40}$

Genetic counselors. According to the American Board of Genetic Counseling, there are presently $\sim 5172$ certified genetics counselors in the United States who practice in cancer, prenatal, and pediatric settings located in university medical settings, public/private hospital facilities, and diagnostic laboratories. ${ }^{44,45}$ Presently in the United States, there are discrepant reports as to the presence and severity of a certified genetic counselor (CGC) shortage. A 2016 industry-sponsored workforce study of U.S.-based CGCs for 2017-2026 found that the U.S. CGC workforce had grown by $88 \%$ from 2006 to 2016 , and is projected to expand another $72 \%$ in the next 10 years. ${ }^{46}$ Conflicting with these trends are peerreviewed scientific reports that identify insufficient 
Table 2. Selected Genetics/Genomics Education and Training Resources by Health Care Professional Domain

\begin{tabular}{|c|c|}
\hline Resource name & Website \\
\hline \multicolumn{2}{|l|}{ Multidisciplinary } \\
\hline American Society of Human Genetics (health care providers) & $\begin{array}{l}\text { https://www.ashg.org/press/healthprofessional.shtml } \\
\text { https://www.ashg.org/education/ }\end{array}$ \\
\hline American Society of Health-System Pharmacists & https://www.ashp.org/Pharmacy-Practice/Resource-Centers/Pharmacogenomics \\
\hline Centers for Disease Control and Prevention & https://www.cdc.gov/genomics/resources/educational.htm \\
\hline National Library of Medicine, Precision Medicine & https://ghr.nlm.nih.gov/resources\#precision-medicine \\
\hline NHGRI Genomics Competency and Curricular Resources & $\begin{array}{l}\text { https://www.genome.gov/For-Health-Professionals/Provider-Genomics- } \\
\text { Education-Resources }\end{array}$ \\
\hline Method for Introducing a New Competency (MINC) & https://genomicsintegration.net/ \\
\hline \multicolumn{2}{|l|}{ Physicians } \\
\hline American Academy of Family Physicians & https://www.aafp.org/afp/topicModules/viewTopicModule.htm?topicModuleld=56 \\
\hline American Academy of Pediatrics, Council on Genetics & https://pediatrics.aappublications.org/committee_on_genetics \\
\hline American Board of Medical Genetics and Genomics & http://abmgg.org/ \\
\hline American College of Medical Genetics and Genomics & https://www.acmg.net/ \\
\hline American College of Obstetricians and Gynecologists & $\begin{array}{l}\text { https://www.acog.org/About-ACOG/ACOG-Departments/Genetics?IsMobileSet= } \\
\text { false }\end{array}$ \\
\hline American Medical Association, Precision Medicine & https://www.ama-assn.org/delivering-care/precision-medicine \\
\hline American Society of Clinical Oncology & $\begin{array}{l}\text { https://www.asco.org/practice-policy/cancer-care-initiatives/genetics-toolkit/ } \\
\text { assessing-managing-your-patients-hereditary }\end{array}$ \\
\hline Association of American Medical Colleges & https://www.aamc.org/ \\
\hline Association of Professors of Human and Medical Genetics & https://www.aphmg.org/ \\
\hline Jackson Laboratories Clinical and Continuing Education & https://www.jax.org/education-and-learning/clinical-and-continuing-education\# \\
\hline $\begin{array}{l}\text { Inter-Society Coordinating Committee for Practitioner } \\
\text { Education in Genomics (ISCC) }\end{array}$ & $\begin{array}{l}\text { https://www.genome.gov/For-Health-Professionals/Inter-Society-Coordinating- } \\
\text { Committee-for-Practitioner-Education-in-Genomics }\end{array}$ \\
\hline \multicolumn{2}{|l|}{ Genetic Counselors } \\
\hline American Board of Genetic Counseling & https://www.abgc.net/ \\
\hline National Society of Genetic Counselors & https://www.nsgc.org/ \\
\hline \multicolumn{2}{|l|}{ Registered Nurses } \\
\hline $\begin{array}{l}\text { American Academy of Nursing, Expert Panel } \\
\text { on Genomic Nursing \& Health Care }\end{array}$ & https://www.aannet.org/expert-panels/ep-genomic-nursing-health-care \\
\hline American Nurses Association & https://www.nursingworld.org/practice-policy/nursing-excellence/ethics/genetics/ \\
\hline Global Genomics Nursing Alliance & https://g2na.org/ \\
\hline International Society of Nurses in Genetics (ISONG) & https://www.isong.org/ \\
\hline National Institute of Nursing Research & https://www.ninr.nih.gov/ \\
\hline Omics Nursing Science and Education Network (ONSEN) & https://omicsnursingnetwork.net/ \\
\hline Oncology Nursing Society, Precision Oncology & https://www.ons.org/learning-libraries/precision-oncology \\
\hline
\end{tabular}

CGCs across various specialties and inadequate distribution across geographic locales, particularly rural settings and the southern United States. ${ }^{47}$ To address gaps in coverage, alternative health care delivery models to increase genetic counseling access in CGC-desert areas include telegenetic medicine and interactive web consults, greater health care workforce provider education and training (i.e., registered nurses [RNs], licensed clinical social workers) in CGC-limited settings, group counseling sessions, and cultivation of innovative institutional collaborations between rural facilities and larger academic partners. ${ }^{48-50}$

Nurses. RNs are the largest body of health care provider and play a key role in the provision of health care services to patients, families, and communities. The U.S. nursing workforce consists of 4,015,250 RNs $\left(2,857,180\right.$ directly employed within the United States).$^{51}$ However, there are approximately $n=350$ nurse clini- cian, educator, and scientist members in the professional advocacy organization for genetics/genomics and approximately $n=425$ graduates of the NIH National Institute of Nursing Research's (NINR) Summer Genetics Institute $^{51-53}$ To facilitate content translation to the broader nursing community, essential genetic and genomic competencies, curricula guidelines, and outcome indicators were developed for U.S. entry level and advanced practice nurse programs and were endorsed and implemented by numerous professional nursing accreditation and certification organizations. ${ }^{54,55}$ Knowledge standards for omic science doctoral nursing research programs were recently developed, in addition to genetic and genomic competencies for nursing informatics. ${ }^{56,57}$ Lastly, a new Global Genomics Nursing Alliance (G2NA) aims to increase the integration of genomics into routine patient care in the general nursing community by providing a global catalogue of nursing education competencies and genomic nursing practice resources. ${ }^{58}$ 
Health system implementation frameworks and CDS

A number of learning health systems are pioneering PM advances through the implementation of genomic medicine screening programs to prevent, detect, and treat adverse health outcomes and chronic diseases. Examples of pharmacogenomic and genomic medicine implementation pilots integrated into health care delivery systems include: North Shore University Health System "DNA10K" population health primary care initiative, Intermountain Healthcare precision oncology program, and Geisinger MyCode Community Health Initiative. ${ }^{8,59-66}$

Although the American College of Medical Genetics and Genomics has issued a policy statement advocating for the return of information on 59 medically actionable genes after clinical exome and whole genome sequencing, complexities of incorporating genomic information into routine clinical practice are formidable in the absence of specialized training. ${ }^{67}$

Clinical implementation barriers for genetic tests and technologies are widely cited and contribute considerably to variable health care system uptake, even in the presence of documented clinical effectiveness. ${ }^{68}$ The NHGRI Implementing GeNomics In pracTicE (IGNITE) Network framework identifies best practices and lessons learned to achieve sustainable adoption of genomic technologies in health care systems. ${ }^{69-71}$

Key components of best-practice implementation within health systems are the structured use of genomic information in clinical care that is linked to (and ideally) supported within the EHR to be guided by CDS. CDS "provides clinicians, staff, patients or other individuals with knowledge and person-specific information, intelligently filtered or presented at appropriate times, to enhance health and healthcare." ${ }^{, 72}$

CDS comprises a variety of rules, resources, and interventions that support clinical workflows at the point of health care delivery by a variety of health care providers, including computerized alerts and reminders to practitioners and patients, evidenced-based clinical guidelines, condition or test result-specific order sets, patient data reports and summaries, documentation templates, diagnostic support information, and contextual references to provide accurate health decision making. ${ }^{73}$

There are three levels of CDS, including passive (nonmandatory EHR resources available to a practitioner at the time of health care), asynchronous (provides information to a practitioner outside of clinical workflow such as an inbox message at the start of a workday), and active (presents information needed for decision making during the practitioner's clinical workflow, "just in time"). ${ }^{65}$ There are a wide range of guides and open source tools for genetic test implementation, including but not limited to: NHGRI IGNITE program's Genomic Medicine Knowledge Base, the Pharmacogenomics Clinical Annotation Tool (PharmCAT), the Displaying and Integrating Genetic Information through the EHR (DIGITizE) program, and the CDS knowledge base (CDSKB) ${ }^{74,75}$ For example, the IGNITE SPARK Toolbox feature provides a range of institutional assessment and CDS tools for genetic test implementation within health care systems, such as the CYP2C19 pharmacogenetic test and associated clopidogrel dosing procedure. Given 404 currently FDA approved pharmacogenomic biomarkers used in drug labeling, CDS tools are and will become essential to connecting patient genetic test results to the appropriate pharmacogenomic drug label indication. ${ }^{3}$

A key consideration to the implementation of any genetic test, PM CDS initiative for nongenetics health care providers, is ensuring that CDS alerts are structured into clinical workflows in ways that are not excessively burdensome. ${ }^{75}$ Consequences of poorly implemented CDS are that providers minimize and ignore safety alerts thus jeopardizing patient safety in the event of a true alert that is inappropriately ignored or silenced. ${ }^{76,78}$ Clinician burnout is identified as a key health policy issue requiring immediate action by a number of federal, regional, public, and private stakeholders to preserve well-being of practitioners in addition to providing high-quality and safe clinical care. ${ }^{79}$

There are broader patient safety frameworks available to guide judicious implementation of CDS so that its use achieves the aim of delivering safe and effective clinical interventions optimized for clinician and health care system workflows. Examples include the Health Information Technology (IT) Safety resource from The U.S. Department of Health and Human Services' Office of the National Coordinator for Health Information Technology (ONC), and the Agency for Healthcare Research and Quality Alert Fatigue resource. $^{73,80}$

\section{Discussion}

Health care delivery institutions and systems are beginning to implement genetic tests that are driving PM. Genetic test use is trending up in terms of rapid U.S. market expansion as evidenced by increased annual 
CPT claim registry and utilization outcomes in the commercial sector, particularly for prenatal and oncology applications, resulting in improved diagnostic and therapeutic tools for a wide range of hereditary and complex conditions. However, ELSI of genetic/genomic test implementation continues to be a priority to ensure adequate access and use of these cutting-edge biomedical advances, particularly for marginalized and vulnerable populations and ethnic minorities.

To ensure safe adoption and clinical translation of $\mathrm{PM}$, health care systems have an ethical responsibility to ensure that their providers and front-line staff are prepared to order, use, and interpret genetic test information. In addition to accommodating genomic information use in CDS and EHR infrastructures, health care systems need to pay particular attention to nongeneticist health care provider workforce adequacy and preparedness to ensure safe application of these advances and drive effective workflow implementation.

There are a number of high-quality evidenced-based educational resources and CDS tools available. CDS and point-of-care "just-in-time" alerts and rapid education intervention tools are a primary pathway for health care providers to use and implement PM, but they must be wisely implemented to avoid health care provider alert fatigue and clinician burnout. This field can be particularly hampered by health care system EHR infrastructure limitations that are unable to support CDS innovations and workflow redesigns involving input and feedback from front-line providers. However, health care systems with cultures fostering strong partnerships between administrative leaders and front-line providers and staff, coupled with reasonable goal setting, will help facilitate PM translation interests.

\section{Conclusion}

The (PM) era presents an exciting yet daunting challenge to implement targeted molecular diagnostic and therapeutic treatments using genetic/genomic and omic information into routine health care settings. The fruits of large scale genomic and biobank research initiatives, population health programs, and the proliferation of bioinformatic tools provide learning health systems and front-line health providers powerful resources to prevent and treat a wide range of hereditary and chronic conditions across a wide range of patient care settings. Strategic planning to support health system infrastructure development that is able to incorporate genetic/genomic information, efficient EHR documentation, CDS capacity, and an adequate number of health care providers trained to use genetic/genomic information will ensure ethical and safe adoption of PM clinical translation interests.

\section{Authorship Confirmation Statement}

The author listed designed and performed the literature review, compiled the article draft, reviewed it critically for content, approved the final article before publication submission, and agrees to be held responsible for all aspects of the study in ensuring that questions related to the accuracy or integrity of any part of the study are appropriately investigated and resolved.

\section{Disclaimer}

This study has been exclusively submitted to Systems Medicine and is not under consideration for publication elsewhere. The abstract was submitted and accepted for a podium presentation at the 1st International Conference in Systems and Network Medicine, Applications of Systems Science and Thinking to Biomedicine held on September 11-13, 2019, at Georgetown University in Washington, DC.

\section{Author Disclosure Statement}

No competing financial interests exist.

\section{Funding Information}

This study was funded by an NIH/NINR Postdoctoral Clinical and Translational Intramural Research Training Award.

\section{References}

1. Collins FS, Varmus $\mathrm{H}$. A new initiative on precision medicine. $\mathrm{N}$ Engl J Med. 2015;372:793-795.

2. National Center for Biotechnology Information. Genetic testing registry. www.ncbi.nlm.nih.gov/gtr Accessed February 29, 2020.

3. Food and Drug Administration. Table of pharmacogenomic biomarkers in drug labeling. Science and research, drugs. www.fda.gov/drugs/scienceand-research-drugs/table-pharmacogenomic-biomarkers-drug-labeling Accessed February 29, 2020.

4. The All of Us Research Program Investigators. The "All of Us" research program. N Engl J Med. 2019;381:668-676.

5. NHGRI. eMERGE network.www.genome.gov/Funded-Programs-Projects/ Electronic-Medical-Records-and-Genomics-Network-eMERGE Accessed February 29, 2020.

6. Sudlow C, Gallacher J, Allen N, et al. UK biobank: an open access resource for identifying the causes of a wide range of complex diseases of middle and old age. PLoS Med. 2015;12:1-10.

7. National Academies of Sciences, Engineering, and Medicine. Implementing and evaluating genomic screening programs in health care systems: Proceedings of a Workshop. National Academies Press, Washington, DC. 2018.

8. LevitL, Kim E, McAneny B, et al. Implementing precision medicine in community-based oncology programs: three models. J Onc Prac. 2019;15: 325-329.

9. Auffray C. Interview with a thought leader on systems medicine-Charles Auffray, PhD. Syst Med. 2018;1:11-12. 
10. Auffray $C$, Balling $R$, Barroso $I$, et al. Making sense of big data in health research: towards and EU action plan. Genome Me. 2016;8:1-13.

11. Chan S. Loscalzo J. The emerging paradigm of network medicine in the study of human disease. Circ Res. 2012;111:359-374.

12. El-Manzalawy $Y$, Hsieh $T$, Shivakumar M, et al. Min-redundancy and maxrelevance multi-view feature selection for predicting ovarian cancer survival using multi-omics data. BMC Med Genomics. 2018;11(Suppl 3):71; 21-31.

13. Schussler-Fiorenza Rose $\mathrm{S}$, Contrepois $\mathrm{K}$, Moneghetti KJ, et al. A longitudinal big data approach for precision health. Nat Med. 2019;25:792-804.

14. Clark D, Dhanasekaran S, Petralia F, et al. Integrated proteogenomic characterization of clear cell renal cell carcinoma. Cell. 2019; 179:964-983.

15. Tang HHF, Sly PD, Holt PG, et al. Systems biology and big data in asthma and allergy: recent discoveries and emerging challenges. Eur Respir J 2020;55:1900844.

16. NHGRI. Genomics and medicine. www.genome.gov/health/Genomicsand-Medicine Accessed February 29, 2020.

17. Harvard University Catalyst. Network medicine. A course series on science in biology and medicine. https://catalyst.harvard.edu/services/ networkmedicine Accessed February 29, 2020.

18. NHGRI. Talking glossary of genetic terms. Personalized medicine. www .genome.gov/genetics-glossary/Personalized-Medicine Accessed February 29, 2020.

19. $\mathrm{NCl} . \mathrm{NCl}$ dictionary of cancer terms. Precision medicine. www.cancer.gov/ publications/dictionaries/cancer-terms/def/precision-medicine Accessed February 29, 2020.

20. Georgetown University Medical Center. First international conference in systems and network medicine: Application of systems science and thinking to biomedicine. Systems medicine definition. https://sites .google.com/georgetown.edu/sysmedconf/home Accessed February 29, 2020.

21. CDC. Precision health: Improving health for each of us and all of us. www .cdc.gov/genomics/about/precision_med.htm Accessed February 29, 2020.

22. Khoury MJ, Galea S. Will precision medicine improve population health? JAMA. 2016;316:1357-1358.

23. Xu J, Yang $P$, Xue $S$, et al. Translating cancer genomics into precision medicine with artificial intelligence: applications, challenges, and future perspectives. Hum Genet. 2019;W138:109-124.

24. National Academies of Sciences, Engineering, and Medicine. An Evidence Framework for Genetic Testing. Health and Medicine Division, Board on Healthcare Services, Board on the Health of Select Populations; Committee on the Evidence Base for Genetic Testing. National Academies Press, Washington, DC. 2017.

25. Paker L, Sankar P, Boyer J, et al. Normative and conceptual ELSI research: what it is, and why it is important. Gen Med. 2019;21:505-509.

26. NHGRI. ELSI research domains. www.genome.gov/Funded-ProgramsProjects/ELSI-Research-Program/domains Accessed February 29, 2020.

27. Ginsburg G, Phillips K. Precision medicine: from science to value. Health Aff. 2018;37:694-701.

28. CDC. Public health genomics and precision health knowledge base (v6.0). https://phgkb.cdc.gov/PHGKB/phgHome.action?action=home Accessed February 29, 2020

29. Parkinson D, McCormack R, Keating S, et al. Evidence of clinical utility: an unmet need in molecular diagnostics for patients with cancer. Clin Cancer Res. 2014;20:1428-1444.

30. Phillips K, Deverka P, Hooker G, et al. Genetic test availability and spending: where are we now? Where are we going? Health Aff. 2018;37: 710-716

31. Cheong Q, Chilukuri S, Quigley D, et al. Genetic Testing: Opportunities to Unlock Value in Precision Medicine. Pharmaceuticals \& Medical Products. 2018. McKinsey \& Company: 1-7. www.mckinsey.com/industries/ pharmaceuticals-and-medical-products/our-insights/genetic-testingopportunities-to-unlock-value-in-precision-medicine Accessed February 29, 2020.

32. Trosman J, Weldon C, Gradishar W, et al. From the past to the present insurer coverage frameworks for next-generation tumor sequencing. Value Health. 2018:21;1062-1068.

33. Korf B, Berry A, Limson M, et al. Framework for development of physician competencies in genomic medicine: report of the competencies working group of the Inter-Society Coordinating Committee for physician education in genomics. Gen Med. 2014;16:804-809.
34. Talwar D, Tseng T, Foster M, et al. Genetics/genomics education for nongenetic health professionals: a systematic review. Gen Med. 2017;19: 725-732.

35. Reed $E$, Taber $L$, Nissen $T$, et al. What works in genomics education: outcomes of an evidenced-based instructional model for communitybased physicians. Gen Med. 2016;18:737-745.

36. Calzone K, Jenkins J, Culp S, et al. Hospital nursing leadership led interventions increased genomic awareness and education intent in Magnet settings. Nurs Outlook. 2018;66:244-253.

37. Hyland K, Garber K, Dasgupta S. From helices to health: undergraduate medical education in genetics and genomics. Pers Med. 2019;16:211-220.

38. Pan V, Rashar B, Pothast $R$, et al. Expanding the genetic counseling workforce: program directors' views on increasing the size of genetic counseling graduate programs. Gen Med. 2016;18:842-849.

39. Health Resources and Services Administration (HRSA). State Level Projec tions of Supply and Demand for Behavioral Health Occupations: 2016-2030. Technical documentation for HRSA health workforce simulation model. Bureau of Health Workforce National Center for Health Workforce Analysis. Rockville, MD: DHHS. 2018.

40. Cichon M, Feldman G. Opportunities to improve recruitment into medical genetics residency programs: survey results of program directors and medical genetics residents. Gen Med. 2014;16:413-418.

41. Ferreira C, Regier D, Hadley D, et al. Medical genetics and genomic medicine in the USA. Part 1: history, demographics, legislation and burden of disease. Mol Gene Genomic Med. 2017;5:307-316.

42. Regier D, Ferreira $C$, Hart $S$, et al. Medical genetics and genomic medicine in the USA. Part 2: reproductive genetics, newborn screening, genetic counseling, training, and registries. Mol Genet Genomic Med. 2017;5: 621-630.

43. American Board of Medical Genetics and Genomics. Number of ABMGG certified specialists in genetics and genomics by examination year. http:// www.abmgg.org/pdf/Statistics\%20for\%20Webpage.pdf Accessed February 29, 2020.

44. American Board of Genetic Counseling, Inc. ABGC is now 5000 strong and growing. www.abgc.net/for-diplomates Accessed February 29, 2020.

45. National Society of Genetic Counselors. Genetic counselor workforce initiatives. Does a genetic counselor workforce shortage exist. www.nsgc .org/page/genetic-counselor-workforce-initiatives-532 Accessed February 29, 2020

46. The Genetic Counselor Workforce Working Group. Workforce study executive study. 2016. www.abgc.net/research-resources/latest-research Accessed February 29, 2020

47. Villegas $C$, Haga $S$. Access to genetic counselors in the southern United States. J Pers Med. 2019;9:1-12.

48. Boothe E, Kaplan J. Using telemedicine in Mississippi to improve patient access to genetic services. J Gen Serv. 2018;27:320-322.

49. Cohen S, Huziak R, Gustafson S. Analysis of advantages, limitations, and barriers of genetic counseling service delivery models. J Gen Counsel. 2016;25:1010-1018.

50. Gammon B, Otto L, Wick M, et al. Implementing group prenatal counseling for expanded noninvasive screening options. J Gen Counsel. 2018 27:894-901.

51. National Council for State Boards of Nursing. Progress and precision: the NCSBN environmental scan. J Nur Reg. 2018;8:S3-S6.

52. Hickey K, Taylor J, Barr T, et al. Nursing genetics and genomics: the international society of nurses in genetics (ISONG) survey. Nur Educ Tod. 2018;63:12-17.

53. NINR. Training at NINR (NIH campus). Summer genetics institute. www ninr.nih.gov/training/trainingopportunitiesintramural/summergenetics institute Accessed February 29, 2020.

54. Calzone K, Jenkins J, Prows $C$, et al. Establishing the outcome indicators for the essential for the essential nursing competencies and curricular guidelines for genetics and genomics. J Prof Nur. 2011;27:179-191.

55. Greco K, Tinley S, Seibert D. Development of the essential genetic and genomics competencies for nurses with graduate degrees. Ann Rev Nur Res. 2011:29:173-190.

56. McCormick K, Calzone K. Genetic and genomic competencies for nursing informatics internationally. Stud Health Technol Inform. 2017;232: 152-164.

57. Regan $M$, Engler $M$, Coleman $C$, et al. Establishing the genomic knowledge matrix for nursing science. J Nur Schol. 2019;51:50-57. 
58. Calzone K, Kirk M, Tonkin E. Increasing nursing capacity in genomics: overview of existing global genomics resources. Nur Educ Today. 2018;69: 53-59.

59. North Shore University Health System. NorthShore and color unlock the power of genomics in routine care. www.northshore.org/newsroom/ press-releases/northshore-and-color-unlock-the-power-of-genomics-inroutine-care Accessed February 29, 2020.

60. Lemke A, Thompson J, Hulick PJ, et al. Primary care physician experiences utilizing a family health history tool with electronic health-record integrated clinical decision support: an implementation process assessment. J Community Genet. 2020:1-12. DOI: 10.1007/s12687-020-00454-8

61. Manickam M, Buchanan A, Schwartz M, et al. Exome sequencing-based screening for BRCA $1 / 2$ expected pathogenic variants among adult biobank participants. JAMA Open. 2018;1:1-14.

62. National Academies of Sciences, Engineering, and Medicine. GenomicsEnabled Learning Health Care Systems: Gathering and Using Genomic Information to Improve Patient Care and Research. Workshop summary. National Academies Press, Washington, DC. 2015.

63. Nadauld L, Ford J, Pritchard D. Strategies for clinical implementation: precision oncology at three distinct institutions. Health Aff. 2018;37:751-756.

64. Poonen, P, Duffy, J, Hintze, B, et al. Genomic analysis of metastatic solid tumors in veterans: findings from the VHA national precision oncology program. J Clin Oncol. 2019;37 (suppl):1-13.

65. Williams M. Early lessons from the implementation of genomic medicine programs. Ann Rev Gen Hum Gen. 2019;20:389-411.

66. Williams W, Buchanan A, Davis F, et al. Patient-centered precision health in a learning health care system: Geisinger's genomic medicine experience. Health Aff. 2018;37:757-764.

67. Kalia S, Adelman K, Bale SJ, et al. Recommendations for reporting of secondary findings in clinical exome and genome sequencing, 2016 update (ACMG SF v2.0): a policy statement of the American College of Medical Genetics and Genomics. Gen Med. 2017;19:249-255.

68. Zebrowski A, Ellis D, Barg F, et al. Qualitative study of system level factors related to genomic implementation. Gen Med. 2019;21:1534-1540.

69. Cavallari L, Beitelshees A, Blake K, et al. The IGNITE pharmacogenetics working group: an opportunity for building evidence with pharmacogenetic implementation in a real-world setting. Clin Trans Sci. 2017;10:143-146.

70. Levy K, Blake K, Fletcher-Hoppe C, et al. Opportunities to implement sustainable genomic medicine program: lessons learned from the IGNITE network. Gen Med. 2019;21:743-747.

71. Sperber N, Carpenter J, Cavallari L, et al. Challenges and strategies for implementing genomic services in diverse settings: experiences from the Implementing GeNomics In practice (IGNITE) network. BMC Med Gen. 2017;10: 1-11.

72. Office of the National Coordinator for Health Information Technology. (2019). Health IT safety. What is clinical decision support. www.healthit .gov/topic/safety/clinical-decision-support Accessed February 29, 2020.

73. Office of the National Coordinator for Health Information Technology. (2019). Health IT safety.www.healthit.gov/topic/health-it-safety Accessed February 29, 2020
74. IGNITE. Genomic medicine knowledge base (GMKB). The knowledge hub for genomic medicine. https://gmkb.org Accessed February 29, 2020.

75. Volpi S, Bult C, Chisholm R, et al. Research directions in the clinical implementation of pharmacogenomics-An overview of US programs and projects. Clin Pharm Ther. 2018;103:778-786.

76. Ancker J, Edwards A, Nosal S, et al. Effects of workload, work complexity, and repeated alerts on alert fatigue in a clinical decision support system. BMC Med Inf Dec Mak. 2017;17:1-9.

77. Baysari M, Zheng W, Li L, et al. Optimising CDS to transform medication safety and reduce prescriber burden: study protocol for a mixedmethods evaluation of drug-drug interaction alerts. BMJ Open. 2019;9: $1-7$

78. ECRI Institute. Top 10 patient safety concerns for health care organizations in 2017. www.ecri.org/EmailResources/PSRQ/Top10_2017/HRC Apr17Reporter_Top10_final.pdf Accessed February 29, 2020.

79. National Academies of Sciences, Engineering, and Medicine. Taking Action Against Clinician Burnout: A Systems Approach to Professional Wellbeing. Washington, DC: National Academies Press. 2019.

80. Agency for Healthcare Research and Quality. Patient safety primer. Alert fatigue. https://psnet.ahrq.gov/primer/alert-fatigue Accessed February 29, 2020.

Cite this article as: Kurnat-Thoma E (2020) Educational and ethical considerations for genetic test implementation within health care systems, Network and Systems Medicine 3:1, 58-66, DOI: 10.1089/ nsm.2019.0010.

Abbreviations Used
$\mathrm{CDS}=$ clinical decision support
$\mathrm{CGC}=$ certified genetic counselor
$\mathrm{CLIA}=$ Clinical Laboratory Improvement Amendments
$\mathrm{CPT}=$ current procedural terminology
$\mathrm{EHR}=$ electronic health record
$\mathrm{ELSI}=$ ethical, legal, and social implications
$\mathrm{eMERGE}=$ electronic Medical Records and Genomics
$\mathrm{FDA}=$ Food and Drug Administration
$\mathrm{IGNITE}=$ Implementing GeNomics In pracTicE
$\mathrm{NCBI}=$ National Center for Biotechnology Information
$\mathrm{NHGRI}=$ National Human Genome Research Institute
$\mathrm{NIH}=$ National Institutes of Health
$\mathrm{NINR}=$ National Institute of Nursing Research
$\mathrm{PM}=$ precision medicine
$\mathrm{RN}=$ registered nurse

\begin{tabular}{|c|c|}
\hline \multicolumn{2}{|c|}{ Publish in Network and Systems Medicine } \\
\hline $\begin{array}{l}\text { NETWORK and SYSTEMS } \\
\text { MEDICINE }\end{array}$ & $\begin{array}{l}\text { - Immediate, unrestricted online access } \\
\text { - Rigorous peer review } \\
\text { - Compliance with open access mandates } \\
\text { - Authors retain copyright } \\
\text { - Highly indexed } \\
\text { - Targeted email marketing }\end{array}$ \\
\hline & liebertpub.com/nsm \\
\hline
\end{tabular}

